\title{
Blastic Plasmacytoid Dendritic Cell Neoplasm: Progress in Cell Origin, Molecular Biology, Diagnostic Criteria and Therapeutic Approaches"
}

\author{
Wei CHENG ${ }^{1}$, Tian-tian YU ${ }^{1}$, Ai-ping TANG ${ }^{1}$, Ken HE YOUNG ${ }^{2}$, Li YU ${ }^{1 \#}$ \\ ${ }^{1}$ Department of Hematology, the Second Affiliate Hospital of Nanchang University, Nanchang 330006, China \\ ${ }^{2}$ Division of Hematopathology and Department of Pathology, Duke University Medical Center, Durham 27710, USA
}

(C) The Author(s) 2021

\begin{abstract}
Summary: Blastic plasmacytoid dendritic cell neoplasm (BPDCN) is a rare hematological malignancy characterized by recurrent skin nodules, an aggressive clinical course with rapid involvement of hematological organs, and a poor prognosis with poor overall survival. BPDCN is derived from plasmacytoid dendritic cells (pDCs) and its pathogenesis is unclear. The tumor cells show aberrant expression of CD4, CD56, interleukin-3 receptor alpha chain (CD123), blood dendritic cell antigen 2 (BDCA 2/CD303), blood dendritic cell antigen 4 (BDCA4) and transcription factor (E protein) E2-2 (TCF4). The best treatment drugs are based on experience by adopting those used for either leukemia or lymphoma. Relapse with drug resistance generally occurs quickly. Stem cell transplantation after the first complete remission is recommended and tagraxofusp is the first targeted therapy. In this review, we summarize the differentiation of BPDCN from its cell origin, its connection with normal pDCs, clinical characteristics, genetic mutations and advances in treatment of BPDCN. This review provides insights into the mechanisms of and new therapeutic approaches for BPDCN.
\end{abstract}

Key words: blastic plasmacytoid dendritic cell neoplasm; plasmacytoid dendritic cell; genetic mutations; immunophenotype; therapeutics

Blastic plasmacytoid dendritic cell neoplasm (BPDCN) was initially described by Adachi et al[1], who reported a 67-year-old Japanese man with a novel dermic lymphoma. The lymphoma was characterized by an aggressive clinical course with progression to the bone marrow and the central nervous system quickly and a $\mathrm{CD} 2^{-}, \mathrm{CD}^{+}$, and $\mathrm{CD}_{5} 6^{+}$immunophenotype. More cases were reported of this disease with a tendency for skin involvement and expression of CD56. However, its origins remain unclear, and subsequently, the disease was called agranular $\mathrm{CD} 4^{+}$ natural killer cell leukemia; agranular $\mathrm{CD}_{4}^{+}, \mathrm{CD} 56^{+}$ hematodermic neoplasm; blastic natural killer cell lymphoma/leukemia, and other names ${ }^{[2-4]}$. With understanding of BPDCN, the entity was classified as a precursor neoplasm of acute myeloid leukemia (AML) in the 2008 revision of the World Health Organization classification of hematopoietic tumors and as a distinct form of AML in the 2016 revision ${ }^{[5,6]}$.

The characteristics and mechanisms of BPDCN are not well understood. BPDCNs originate from

Wei CHENG, E-mail: wweicl@163.com

\#Corresponding author, E-mail: ndefy02021@ncn.edu.cn, zengyulii@126.com

*This work was supported by the National Natural Science Foundation of China (No. 81460030, 81770221). plasmacytoid dendritic cells $(\mathrm{pDCs})^{[7-10]}$. Although BPDCN cells and pDCs both express the molecular markers interleukin-3 receptor alpha chain (CD123), blood dendritic cell antigen 2 (BDCA 2/CD303), CD2AP, CD4, and T cell lymphoma antigen 1 (TCL1) and transcription factors such as transcription factor (E protein) E2-2 (TCF4), interferon regulatory factor 7 (IRF7), interferon regulatory factor 8 (IRF8), BCL11A, and SPIB ${ }^{[1-18]}$, the two cell types have different cell morphologies, functions, molecular markers, and gene expression. Chaperot et al[ ${ }^{[7]}$ reported that $\mathrm{CD} 4^{+}$, $\mathrm{CD} 6^{+}$hematological neoplasms generated interferon 1 (IFN1) in response to the influenza virus; those neoplasms could transform into dendritic cells (DCs) upon the stimulation of interleukin-3 (IL-3), expressed major histocompatibility complex class II (MHCII), and potently stimulated the polarization of naive $\mathrm{T}$ cells and Th2 cells, confirming a leukemic counterpart of pDC. Sapienza et al further discovered that gene expression levels of BPDCNs are similar to those of myeloid-derived resting $\mathrm{pDCs}$, and this similarity could explain the absence of IFN1-producing genes between BPDCNs and resting pDCs; meanwhile, the nuclear factor kappa B (NF- $\mathrm{kB}$ ) pathway that is abnormally activated in BPDCNs might be a new therapy target ${ }^{[19]}$.

This review summarizes the current studies on the different biological, molecular, ontogenetic, 
morphological, and functional features of BPDCNs and pDCs. Recent advances have greatly enhanced our understanding of BPDCNs and have led to new insights into mechanisms involved in dysregulated gene expression in pDCs and BPDCNs. The new knowledge has pointed to new therapeutic approaches for patients with BPDCN.

\section{CHARACTERISTICS, DEVELOPMENT AND FUNCTIONS OF NOMAL PDCS}

\subsection{Distribution and Morphology of Normal pDCs}

pDCs were formerly called "plasmacytoid T cells" or plasmacytoid T-zone cells ${ }^{[20,21]}$. Later, they were named plasmacytoid monocytes because they have some myelomonocytic markers, such as CD15 and CD68, and lack other specific T-lineage markers ${ }^{[22]}$. The term pDCs was adopted after their origin and biological function were better understood ${ }^{[23-25]}$. Functionally, pDCs are a subpopulation of DCs; the other subpopulation of DCs is conventional DCs (cDCs), which play an important role in the immune system by processing and presenting antigens and then exerting their role in phagocytosis and stimulating the proliferation of specifically cytotoxic $\mathrm{T}$ cells and Th2 cells ${ }^{[26]}$. pDCs display an intermediate-size, round-ovoid shape, an eccentric nucleus, scattered fine chromatin, small but distinctive nucleoli, dark basophilic cytoplasm with a pale Golgi zone, and abundant rough endoplasmic reticulum ${ }^{[27]}$. Nodal pDCs are present in clusters or dispersed near high endothelial venules ${ }^{[28]}$. In other lymphoid tissues, pDCs are dispersed and never aggregated.

pDCs, produced in the bone marrow, account for a proportion of less than $0.05 \%$ of mononuclear cells in blood ${ }^{[29]}$. Most pDCs are located in lymph nodes and tonsils, and small quantities can be found in the spleen, thymic medulla, and mucosa-associated tissue $^{[28,30]}$, whereas pDCs are almost never found in other lymphoid tissues and peripheral nonlymphoid tissues $^{[21]}$. Activation of an immune response induces the accumulation of pDCs in lymphoid tissues ${ }^{[23]}$, while the recruitment of pDCs to nonlymphoid tissues suggests an inflammatory or neoplastic state ${ }^{[31-33]}$. The abnormal activation of pDCs could lead to KikuchiFujimoto disease, Hodgkin disease, Castleman disease, and autoimmune diseases ${ }^{[23,31-33]}$.

\section{2 pDCs Development}

Early hematopoietic myeloid progenitors differentiate into common dendritic cell progenitors (CDPs) through macrophage-DC progenitors or produce CDPs directly ${ }^{[34-37]}$. CDPs then differentiate into cDCs or $\mathrm{pDCs}$, a process controlled by lineagespecific regulatory signals ${ }^{[38-40]}$. Rodrigues et $a l^{[41]}$ reported that $\mathrm{pDCs}$ develop predominantly from Lin $^{-} \mathrm{c}-\mathrm{Kit}^{\text {int-lo }}{ }^{\mathrm{F}} \mathrm{lt}{ }^{+} \mathrm{M}-\mathrm{CSFR}-\mathrm{IL}-7 \mathrm{R}^{+}$cells, which possess major $\mathrm{pDC}$ differentiation potential and $\mathrm{pDC}$ lineage specification at the $\mathrm{Ly}_{6} \mathrm{D}^{+}$Siglec $\mathrm{H}^{+}$progenitor stage; such pDCs mostly show pure pDC properties, unlike a small group of pDCs called "pDC-like" cells, which are derived from CDPs and share functional properties with cDCs. pDCs and pDCs-like cells share phenotypic similarities but have distinct transcription and function ${ }^{[41,42]}$. In the bone marrow, both pDCs and cDCs could be developed from CDPs, and FMS-related tyrosine kinase 3 (FLT3) ligands function as the critical cytokines for the development and differentiation of both $\mathrm{pDCs}$ and $\mathrm{cDCs}^{[43,44]}$ (fig. 1). However, the mechanisms of regulatory signals that control lineage diversification have not yet been clearly illustrated.

Efforts have been undertaken to identify the regulatory and developmental factors that affect pDCs and $\mathrm{CDCs}^{[40,45-49]}$. TCF4 plays a key regulator function in commitment to and maintenance of pDC lineage by controlling the transcriptional network. Its absence induces a conversion from $\mathrm{pDC}$ to $\mathrm{cDC}$ lineage ${ }^{[45-48]}$. Further, the loss of ID-2 (an E-box transcription factor inhibitor target that is necessary for $\mathrm{cDC}$ development), transforms cDCs into $\mathrm{pDCs}^{[47]}$. PU.1, an ETS-domain transcription factor, is able to control the expression of the cytokine receptors FLT3, M-CSFR, and GMCSFR, which are indispensable for the development of all $\mathrm{DCs}^{[40,48,49]}$. The interferon-regulatory factor IRF2 can change pDC proportions by inhibiting IFN1 genetic transcription, which is mediated by IRF1 ${ }^{[49]}$. Other transcription factors controlling $\mathrm{pDC}$ development, such as IRF8 (ICSBP), zinc-finger DNAbinding protein Ikaros, growth factor independent 1 (GFI1), and SPIB, are necessary for both pDC and cDC development ${ }^{[40,48,49]}$. However, STAT5 inhibits pDC development by suppressing the IRF8 pathway ${ }^{[49,50]}$. Additionally, TCF4 directly targets transcription factors such as SPIB, IRF8, BDCA2, ILT7, PTCRA, and IRF7 in pDCs, whileas these genes, in turn, regulate TCF4 expression; therefore, these factors constitute a TCF4-orchestrated regulatory network that maintains $\mathrm{pDC}$ lineage identity ${ }^{[45-47,49]}$. Collectively, $\mathrm{cDC}$ and $\mathrm{pDC}$ lineage development requires both $\mathrm{E}$ proteins and the PU.1-IRF8 axis working together ${ }^{[49]}$, but the interactions between the E2-2-ID-2 and PU.1IRF8 axes need further investigation to discover the identities of transcription factor-targeted genes.

\subsection{Function and Heterogeneity of pDCs}

The pDCs bridge the innate and adaptive immune systems mainly by recognizing nucleic acid sequences and working as antigen-presenting cells, a process that is mediated by the toll-like receptor (TLR) 7/9-MyD88IRF7 pathway ${ }^{[51-54]}$. In the setting of inflammatory response, $\mathrm{pDCs}$ generate a set of cytokines dominated by IFN- $\alpha$ and inflammatory chemokines such as IL6, IL-8, and IL-12. These cytokines bring about the activation of $\mathrm{T}$ cells, natural killer cells, and 


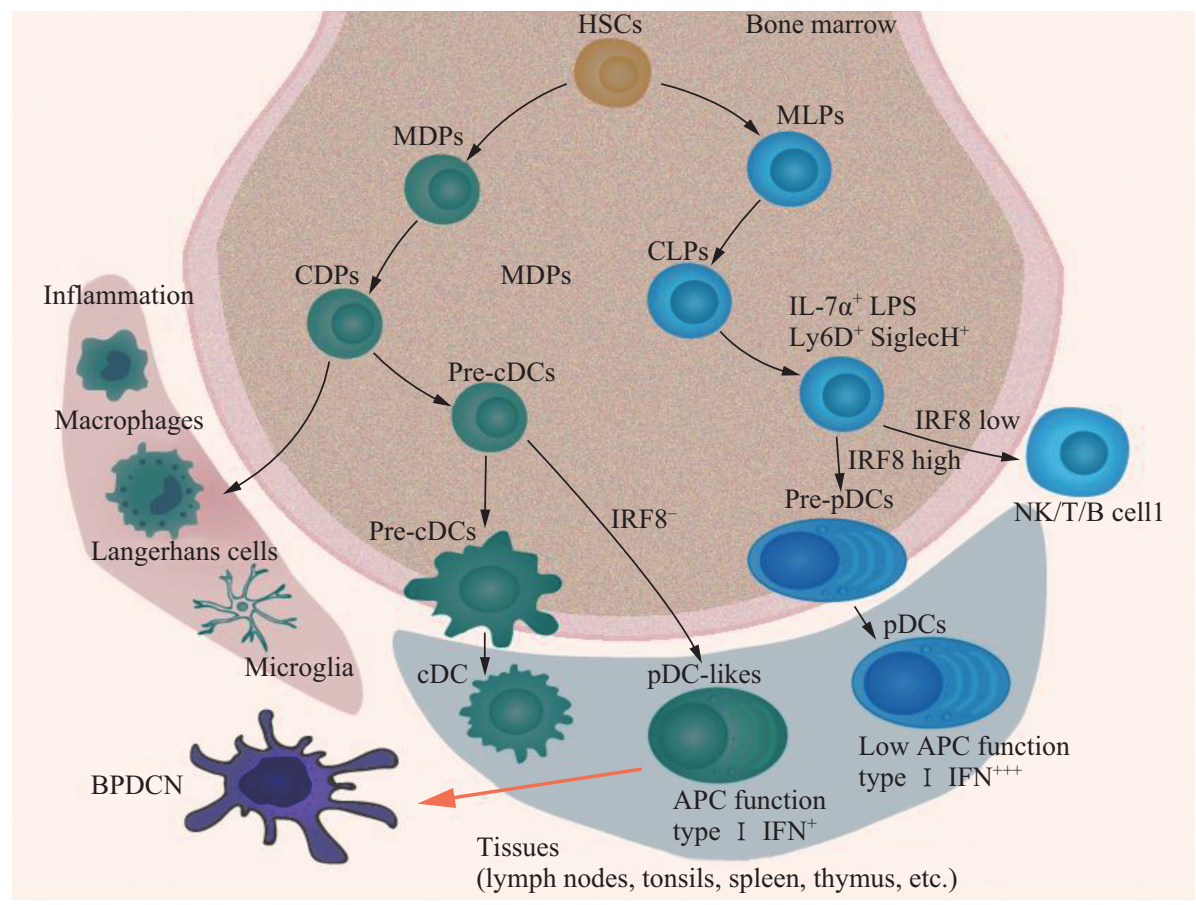

Fig. 1 In the bone marrow, hematopoietic stem cells generate myeloid progenitors (MPs) and lymphoid progenitors MPs differentiate into common dendritic cell progenitors (CDPs) through macrophage-DC progenitors (MDPs) or produce CDPs directly; CDPs then differentiate into conventional dendritic cells (cDCs) or plasmacytoid dendritic cells (pDCs). Most pDC populations in bone marrow and other tissues (including lymph nodes, tonsils, spleen, thymic medulla, and mucosa-associated tissue) originate from an IL- $\mathrm{R}^{+}$progenitor cell population that parallels the previously identified pre-cDC population, while a minor transcriptionally and functionally distinct $\mathrm{pDC}$ population, called $\mathrm{pDC}$-like cells, is independently derived from CDPs. pDCs and pDC-like cells are two distinct cell populations that share phenotypic similarities but are distinct in transcription and function. CDPs: common dendritic cell progenitors; HSCs: hematopoietic stem cells; LPs: lymphoid progenitors; MDPs: macrophage-DC progenitors; MPs: myeloid progenitors; pDCs: plasmacytoid dendritic cells; BPDCN: blastic plasmacytoid dendritic cell neoplasm

macrophages in various adaptive immune responses, including inflammation and autoimmune diseases (fig. 2).

The pDC population is heterogeneous and is classified into two subsets called pure pDCs and pDC-like cells ${ }^{[41,42]}$. Pure pDCs originate from IL-7R ${ }^{+}$ lymphoid progenitors and are capable of producing IFN- $\alpha$ and, to a lesser extent, stimulating T cells. The pDC-like cells are derived from CDPs, highly express MHCII after stimulation by CpG-A, and are capable of processing antigens and prompting $\mathrm{T}$ cell proliferation. They have characteristics that resemble those of cDCs.

\section{GENETIC AND FUNCTIONAL LINKS BETW- EEN PDCS AND BPDCNS}

The genetic background of BPDCN cells shows the heterogeneity of genetic abnormalities. In 2008, Marafioti et al found that 47 pDC-derived neoplasms co-express the majority of pDC-associated markers, including transcription factors (BCL11A, E47, FOXP1, IRF8, and PU.1), signaling molecules (BLNK, BTK, CD2AP, DAP12, IRAK1, Lyn, Syk, and TCB1D4), and receptor molecules [CD79b, toll like receptor 7 (TLR7), and TLR9] ${ }^{[14]}$. Sapienza et al proved that $\mathrm{BPDCNs}$ are derived from resting $\mathrm{pDCs}$ of myeloid origin. The aberrant activation of NF- $\mathrm{kB}$ and upregulation of the cyclin D1 gene (CCND1) and two NF- $\kappa \mathrm{B}$ targets (BCL2 and IRF4) were identified in $\mathrm{BPDCNs}^{[19]}$. Years later, BPDCN cells originating from non-activated pDCs were proposed again because, PTPRS, the gene inhibiting the activation of normal $\mathrm{pDCs}$, was found to be overexpressed in BPDCN, to prevent immune-mediated inflammation, which may be linked with the immune deficiency of BPDCN ${ }^{[55]}$. Recently, Villani et al ${ }^{[56]}$ further demonstrated that BPDCNs co-expressed genes with pDCs and cDCs by single-cell RNA sequencing in four patients with BPDCN. An analysis of the genes similarity between BPDCN cells, pure $\mathrm{pDCs}$, and $\mathrm{cDCs}$ showed that although BPDCNs expressed several pDC-associated genes (e.g., NRP1, IL3RA, DERL3, LAMP5, PTCRA, and PTPRCAP), a set of important functional genes for $\mathrm{pDC}$ were missing or slightly expressed in BPDCN cells (including GZMB, IRF7, CD303, and $S L C 15 A 4)$. Only a fraction of cDC genes (SIGLEC6, LTK, FCER1A, CD59, CADM1, and TMEM14A) were present in BPDCN cells. All the BPDCN samples also expressed some genes associated with B cells (e.g., FCRLA, IGLL1, TCL1A, and IGLL5) or hematological 


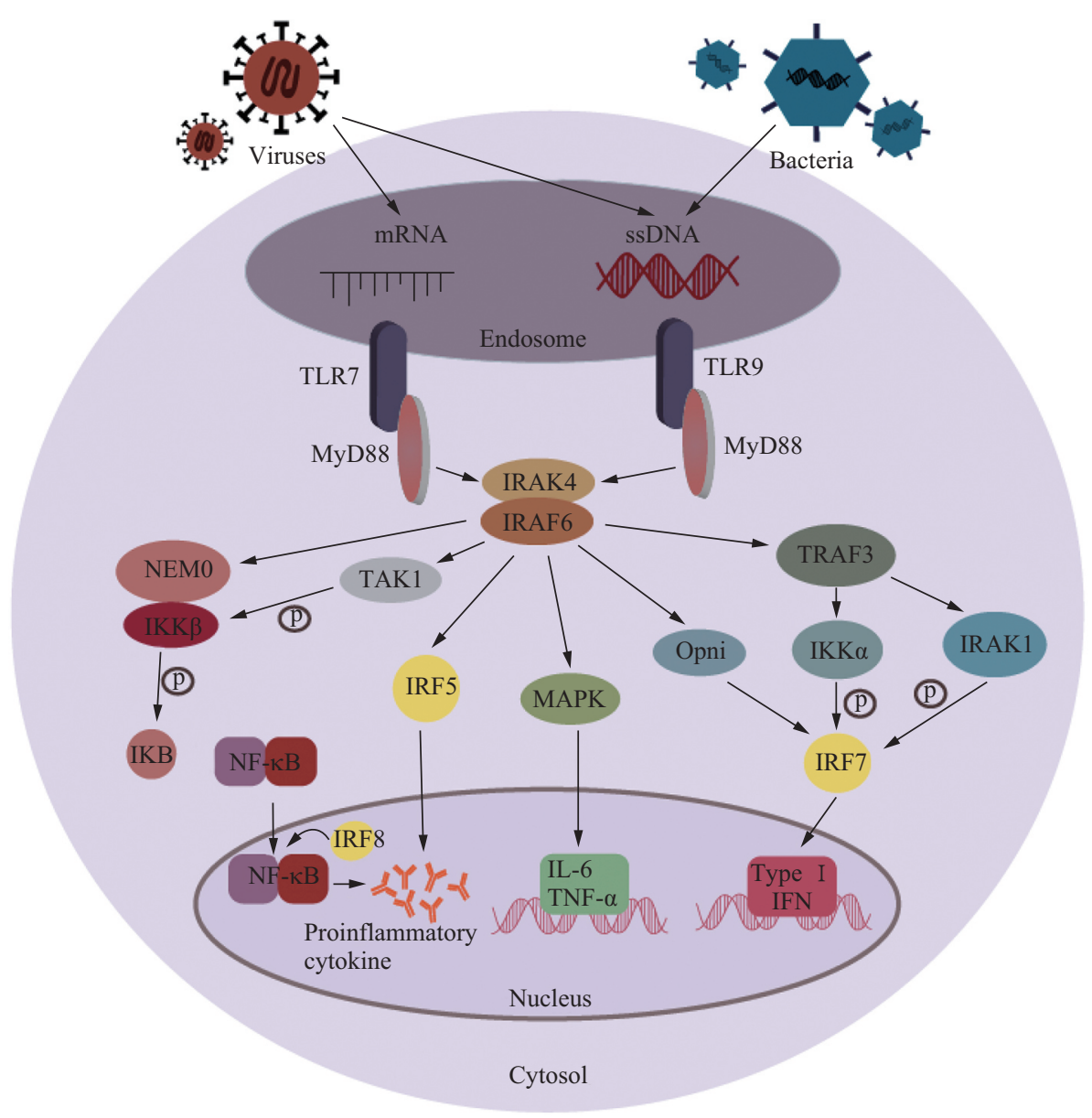

Fig. 2 The activation and regulation modes in the plasmacytoid dendritic cells (pDCs)

In pDCs, viruses and bacteria activate TLR7 and TLR9 through endolysosomes, and UNC93B1 interacts with these TLRs in the endoplasmic reticulum and is essential for this trafficking. Activation of TLR7 or TLR9 recruits MyD88, IRAK4, and TRAF6, which activates IRF5 and NF-kB for inflammatory cytokine induction and IRF7 for type I interferon induction. For IRF7 activation, IRAK1- and IKK $\alpha$-dependent phosphorylation is required, and TRAF3 locates at upstream of these kinases. OPNi is involved in IRF7 activation, and IRF8 facilitates NF- $\mathrm{kB}$ activation. IkB serves as a negative regulator. TRAF6 also activates TAK1, then TAK1 phosphorylates IKK $\beta$ leading to IkB degradation and releasing of NF-kB.

progenitors (e.g., SOX4 and CLEC11A). Despite coexpressing some genes that play key roles in B cell molecular singling, BPDCN cells were found to more closely resemble pDCs. However, these results suggest that the origin and genetic background of BPDCNs are complex and similar to those myeloid-origin resting pDCs.

Notably, TCF4, an indispensable gene in the regulation of $\mathrm{pDC}$ development, may be a driver gene in the transformation of pDCs to BPDCNs. Based on RNAi screening analysis, Ceribelli et $a l^{[57]}$ demonstrated that downregulation of TCF4 led to the loss of BPDCN-specific genetic expression programming and induction of apoptosis. The researchers also found that a subgroup of TCF4-activated oncogenes, including $B C L 2, T C L 1 A / B$, and $M Y C$, were expressed at higher levels in BPDCNs than in pDCs; in contrast, a subset of $T C F 4$-activated functional genes, including $B C L 11 A$, $S P I B, I L 3 R A$, and $C L E C 4 C$, were expressed at higher levels in pDCs than in BPDCNs. Additionally,
TCF4-activated genes were highly enriched for pDC-specific genes $\left(\mathrm{CD}_{2} 3^{+}\right)$. Conversely, TCF4repressed genes were strongly enriched for $\mathrm{cDC}$ genes $\left(\mathrm{CD}^{+} 6^{+}\right.$and $\left.\mathrm{BDCA}^{+}\right)$. This result highlights that TCF4 functions as one of the master regulators in BPDCNs and could be cited as a reliable diagnostic marker of BPDCN. Thus, TCF4 acts as a "lineagesurvival oncogene" of BPDCN. BPDCN cells inherit TCF4 target transcriptional procedures from their normal counterpart cells pDCs, but the pDC-specific function of TCF4 was impaired in BPDCN to support oncogenic gene expression procedures. This is in line with the traditional conception that transcriptional programs inherited from the normal original cell are re-orchestrated to exert the malignant procedures of tumor cells, and those TCF4 upregulated genes may lead to the BPDCN malignant phenotype and clinical behaviour. How TCF4 regulatory network changes from $\mathrm{pDCs}$ to BPDCNs is unclear, and further studies involving driving factors of BPDCN are needed. 


\section{CHROMOSOMAL ABNORMALITIES AND GENETIC MUTATIONS OF BPDCN}

The majority of patients with BPDCN have chromosomal abnormalities detected by conventional karyotyping, and up to $75 \%$ have a complex karyotype $^{[58]}$ (fig. 3). Collectively, previous studies identified frequent chromosomal losses including $5 \mathrm{q} 21$ or $5 \mathrm{q} 32(72 \%), 12 \mathrm{p} 13$ (64\%), 13q13-21 (64\%), $6 \mathrm{q} 23$-ter $(50 \%), 15 \mathrm{q}(43 \%), 9(28 \%)^{[59]}$; other low frequency events $4 \mathrm{q} 34.1-4 \mathrm{q} 34.2,9 \mathrm{p} 13.2-9 \mathrm{p} 11.2,9 \mathrm{q} 12-$ 9q34.3, and 13q12.11-13q31.1; and overexpression of the oncogenes HES6, RUNX2, and FLT3 without the associated genomic amplification ${ }^{[60]}$. Genetic mutations involving TET2, ASXL1, NRAS, and ATM were common, and less common mutations included NPM1, IKZF, KRAS, IDH2, MET, APC, BRAF, KIT, MLH1, RB1, RET, TP53, ZEB2, HOXB9, UBZ2, SRSF2, and $\mathrm{VHL}^{[61-63]}$. Recently, rearrangement of MYC on $8 \mathrm{q} 24$ (in $38 \%$ of patients with BPDCN) or a balanced translocation $\mathrm{t}(6 ; 8)(\mathrm{p} 21 ; \mathrm{q} 24)$ has been reported ${ }^{[64,65]}$, and a high rate of monoallelic and biallelic 12p13/ ETV6 deletions was identified in BPDCN tumors and in the bone marrow of patients with BPDCN without detectable disease, indicating that such alterations may be involved in pathogenesis ${ }^{[6,67]}$.

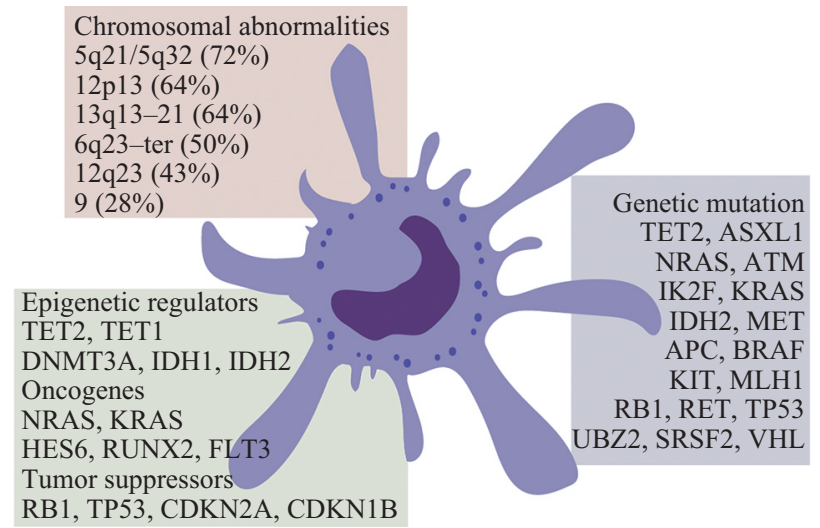

Fig. 3 Schematic representation of pDCs and summary of molecular and immunophenotypic biomarkers in BPDCN Chromosomal abnormalities are shown in pink background. Genetic mutations are shown in grey background. Epigenetic regulators, oncogenes, and tumor suppressors are displayed in green background.

Collectively, inactivation of tumor suppressors $(R B 1, T P 53, C D K N 2 A \text {, and } C D K N 1 B)^{[68]}$, activation of oncogenes (NRAS, KRAS, HES6, RUNX2, and $F L T 3)^{[60,63]}$, and mutations in epigenetic regulators (TET2, TET1, DNMT3A, IDH1, and IDH2 $)^{[69,70]}$ that are also frequently mutated in AML were identified in BPDCN. These findings may explain BPDCN's histological characteristics such as tight accumulation of malignant cells, high aggressiveness, and resistance to chemotherapy (fig. 3).

\section{CLINICAL FEATURES, MICROSCOPIC MOR- PHOLOGY, IMMUNOPHENOTYPE OF BPDCN}

\subsection{Clinical Features}

BPDCNs account for less than $1 \%$ of all hematopoietic neoplasms ${ }^{[71]}$. According to recent Surveillance Epidemiology and End Results (SEER) data, the morbidity of this disease in the United States is 0.04 cases per 100000 individuals $^{[72]}$. BPDCN is more common in men than in women. Although the median age of patients at diagnosis is 53 years, this disease can happen at any age and appears to show a bimodal morbidity pattern that peaks in those younger than 20 years and older than 60 years, according to the SEER data ${ }^{[72]}$.

Cutaneous lesions occur in $64 \%$ of patients with BPDCN and are often the first symptom for patients seeking medical care ${ }^{[73]}$. Julia et a ${ }^{\left[{ }^{[74]}\right.}$ reported that isolated skin damage was frequent (73\% of patients), and cutaneous lesions could vary in size (from a few millimeters to $10 \mathrm{~cm}$ ) and color (erythematous, reddish, or bluish) and present with bruise-like patches (12\%), disseminated lesions (14\%), and mucosal lesions (6\%), as shown in fig. 4. Lymphadenopathy, splenomegaly, and cytopenia caused by bone marrow infiltration at diagnosis or during disease progression can be observed easily; at the same time, thrombocytopenia, anemia, and neutropenia in the peripheral blood can be found frequently because bone marrow is involved ${ }^{[75]}$. Spreading to the central nervous system is common, and approximately one-third of patients with BPDCN has central nervous system involvement when their disease relapses ${ }^{[75,76]}$. Other affected sites include the liver, lung, tonsils, soft tissues, and eyes ${ }^{[8,73,75,77]}$.

A subset of patients with BPDCN displays leukemic manifestations without noticeable cutaneous presentation ${ }^{[75,77,79]}$. In a study reporting the largest number of patients with BPDCN and leukemic manifestations, about $23 \%$ of patients had no skin presentation at diagnosis, and only two had cutaneous manifestations during disease progression ${ }^{[75]}$. A large proportion of patients with BPDCN had a history of myeloid neoplasms, such as acute/chronic myeloid leukemia, chronic myelomonocytic leukemia, or myelodysplastic syndrome ${ }^{[8,80]}$.

\subsection{Microscopic Morphology of BPDCN}

PDCNs are expressed in two unique forms. The first variant, mature pDCs, is associated with myeloid neoplasms, and the other form, termed BPDCN cells, is associated with highly aggressive hematological tumors $^{[18]}$. The morphology of BPDCNs is heterogeneous and complex. Skin biopsies often display a suffused infiltration of monomorphic medium-sized blast cells characterized by irregular, eccentrically located nuclei; finely dispersed chromatin; and one or more small but distinctive nucleoli ${ }^{[8,80-82]}$. The 
cytoplasm is dispersed and never granular. Mitoses are varying in number, and angioinvasion and coagulative necrosis are almost never found. Generally, malignant cells infiltrate the dermis and subcutaneous tissues but do not involve the epidermis ${ }^{[81]}$. Lymph node involvement can be observed, and the tumor cells have an infiltration pattern similar to leukemic cells, which begin in the medulla and then develop in the interfollicular areas until completely infiltrating the lymph nodes and damaging the lymph node structure. Bone marrow involvement is common and may vary from small fractional infiltration to suffused bone marrow dissemination on bone marrow biopsy ${ }^{[83]}$. On blood and marrow smears, tumor cells may show blastoid features similar to lymphoblastic morphology, with cytoplasmic microvacuoles, pseudopodiashaped expansions, and lack of granules or crystals ${ }^{[8]}$. Dysplastic alteration can manifest in the remaining hematopoietic tissues, especially in megakaryocytes ${ }^{[8,}$ ${ }^{84]}$, as displayed in fig. 4.

\subsection{Immunophenotype of BPDCN}

The diagnosis of BPDCN requires immunophe- notyping and fundamentally relies on the expression of the typical CD4, CD56, CD123, CD303, and TCL1 molecular markers and lack of other lineagespecific markers ${ }^{[7-10,16,85]}$ (fig. 4 and table 1). The immunophenotype of a representative patient diagnosed with BPDCN in our hospital is shown in fig. 4 and immunophenotypic features are summarized in fig. 5 . TCF4 can increase the specificity of the diagnosis more than all typical molecular markers identified recently ${ }^{[57]}$. However, atypical immunophenotype is frequently reported, and several other lineage-specific antigens can be present, including $\mathrm{CD} 2, \mathrm{CD} 5, \mathrm{CD} 7, \mathrm{cCD} 3$, CD43, CD45RA, CD68, CD33, CD31, CD34, CD36, CD38, CD79a, CD117, HLA-DR, TdT, BCL2, BCL6, MUM1, and S100. Most of these are variably expressed in BPDCNs, which makes diagnosis difficult, especially when typical markers are absent ${ }^{[15,17,81-83,85-89]}$. To improve the diagnostic methods for BPDCN, many immunophenotype-related studies have proposed multiple suggestions as knowledge of this aggressive disease progresses.

BPDCNs show clinical and immunophenotypic
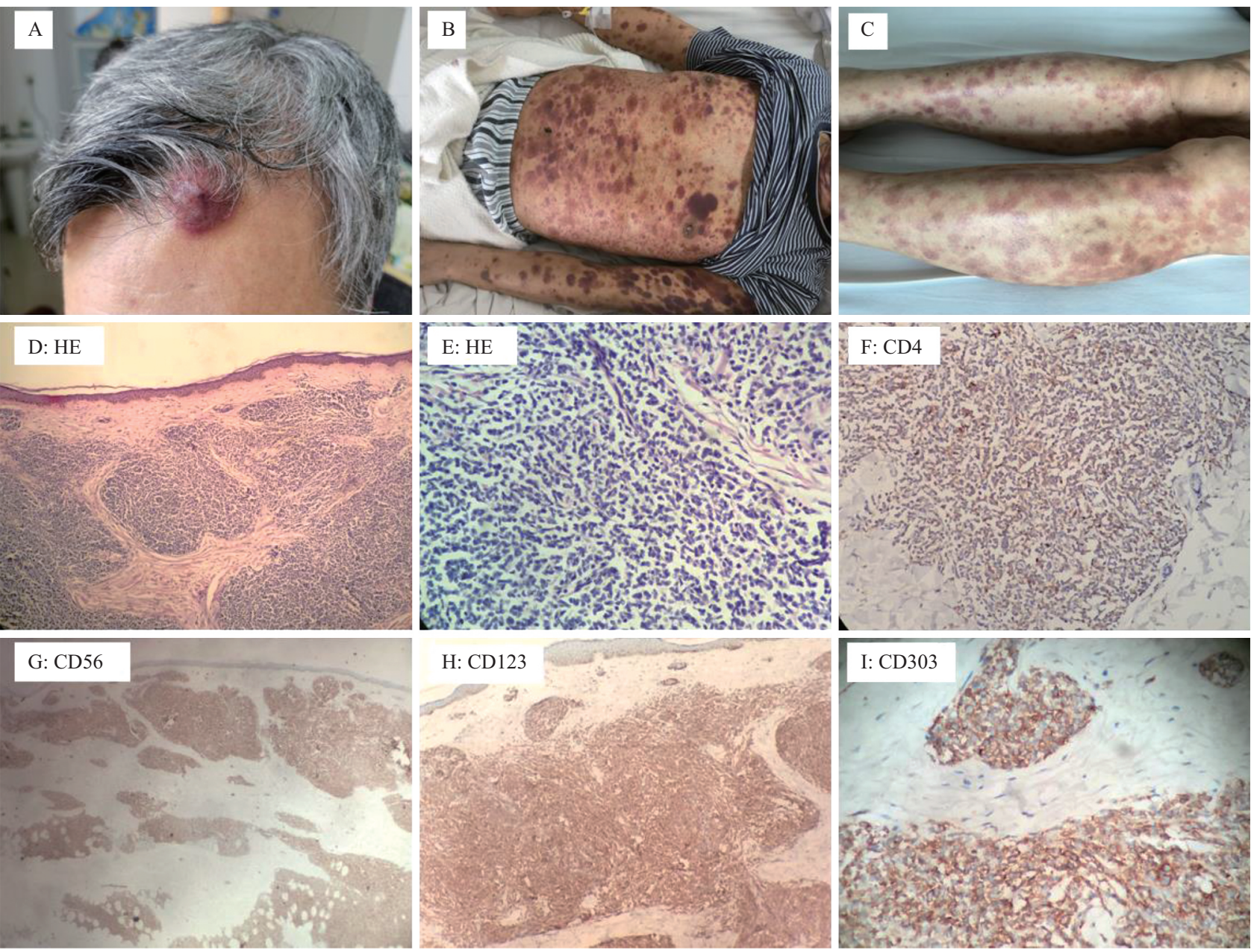

Fig. 4 Representative images showing cutaneous lesions and immunohistochemical expression in patients with BPDCN

A-C: The cutaneous lesions can vary in size (from a few millimeters to $10 \mathrm{~cm}$ ) and color (erythematous, reddish, or bluish) and present with bruise-like patches, disseminated lesions, and mucosal lesions; D and E: HE staining of cutaneous lesions; F-I: Images with expression of CD4 (F), CD56 (G), CD123 (H), and BDCA-2 (CD303) (I). D, G, H (40×); E, F (100×); I (200×) 
Table 1 The summary of BPDCN immunophenotypes

\begin{tabular}{lcl}
\hline Immuno-phenotype & Expression rate (\%) & Characteristics \\
\hline CD45 & 100 & Often located in the blast gate (dim CD45 with a low side scatter) \\
HLA-DR & 100 & Uniform bright in all cases \\
CD123 & 100 & Decreased expression in $84 \%$ of cases \\
CD303 & 25 & Decreased in neoplastic cells: negative expression in $75 \%$ and positive expression in \\
& & $25 \%$ but decreased expression in BPDCNs when compared to reactive pDCs \\
CD56 & 97 & Uniform positivity with the remaining few cases being partially positive \\
CD38 & 70 & Decreased expression \\
CD7 & 69 & Uniform expression in $50 \%$ cases \\
CD2 & 17 & \\
CD33 & 45 & Partial expression in $14 \%$ cases and uniform positivity in the remaining $86 \%$ cases.
\end{tabular}

BPDCN: blastic plasmacytoid dendritic cell neoplasm; ALL: acute lymphoblastic leukemia. pDCs: plasmacytoid dendritic cells

A

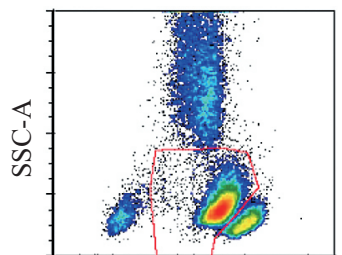

CD45

B

\begin{tabular}{|l|l|}
\hline Biomarkers & Distribution \\
\hline CD2 & $10 \%-20 \%$ \\
\hline CD4 & $100 \%$ \\
\hline CD5 & $1 \%-2 \%$ \\
\hline CD7 & $70 \%-80 \%$ \\
\hline CD33 & $40 \%-60 \%$ \\
\hline CD36 & $50 \%-60 \%$ \\
\hline CD38 & $70 \%-80 \%$ \\
\hline CD45 & $100 \%$ \\
\hline CD56 & $95 \%-100 \%$ \\
\hline CD117 & $5 \%-10 \%$ \\
\hline CD123 & $100 \%$ \\
\hline CD303 & $70 \%-80 \%$ \\
\hline HLA-DR & $100 \%$ \\
\hline MYC & $20 \%-50 \%$ \\
\hline TDT & $5 \%-20 \%$ \\
\hline TCL-1 & $90 \%-100 \%$ \\
\hline
\end{tabular}

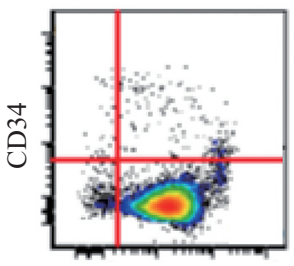

CD33

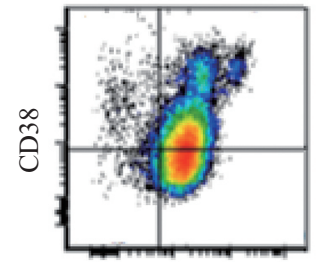

CD33

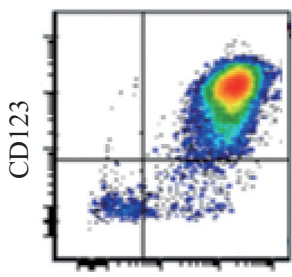

HLA-DR

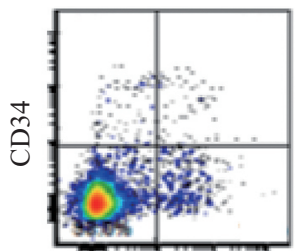

CD13

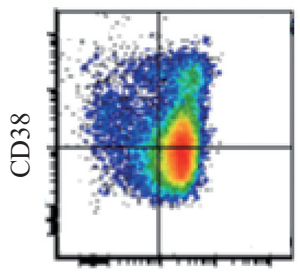

CD4

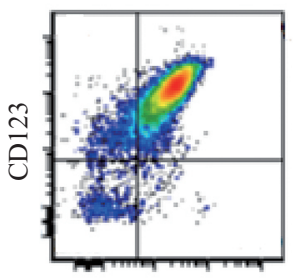

CD4

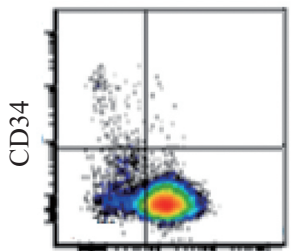

CD7

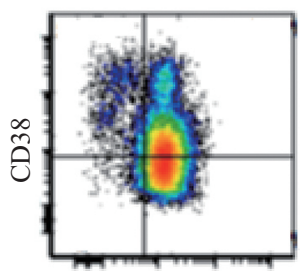

CD7

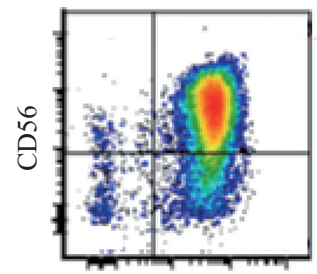

HLA-DR

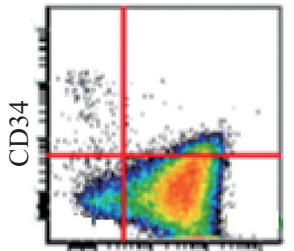

CD56

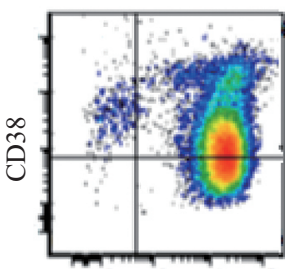

HLA-DR

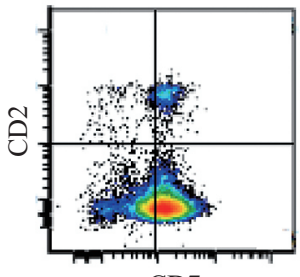

CD7

Fig. 5 Schematic representation and summary of immunophenotypic profiling in BPDCN by flow cytometry A: Representative flow cytometry plots show critical biomarker expression in patients with BPDCN. B: biomarkers distribution in patients with BPDCNs

heterogeneity, and some studies have been conducted to account for this heterogeneity in diagnosing the disease. Garnache-Ottou et $a l^{[85]}$ developed a scoring system for diagnosis of BPDCN using a large series of markers based on flow cytometry of 20 BPDCN cases and 113 lymphoid and myeloid acute leukemia cases. They identified the expression of CD4 $\left(\mathrm{CD}^{+/-}\right)$and lack of CD11c, cCD3, cCD79a, and MPO scored 1 point; CD123high and BDCA4+ scored 1 point each; and the expression of BDCA2 scored 2 points. The diagnosis of BPDCN is trustworthy when the total score is more than two points, which is applicable for typical or atypical
BPDCN immunophenotype. Julia et al ${ }^{[82]}$ described that the co-expression of the five most common markers, CD4, CD56, CD123, CD303, and TCL1, only occurred in $46 \%$ of patients with BPDCN. Based on an analysis of the immunohistochemical marker expression in skin biopsies for 91 well-documented cases, a confident diagnosis could be built when four of these five markers are present. The molecular markers CD2AP and SPIB were also identified as contributors to the diagnosis for BPDCN ${ }^{[14,15,17]}$. The typical immunophenotypes of BPDCN are summarized in fig. 5.

The fact that BPDCNs show clinical and 
immunophenotypic heterogeneity is undoubted; however, the connection between these tumors' clinical behavior and phenotype has not been identified, and the different phenotypic maturation stages are unknown. Some studies have since tried to shed light on these problems. Julia et $a^{[82]}$ found that $\mathrm{TdT}^{-} /$ $\mathrm{S} 100^{+} \mathrm{BPDCN}$ cells are more mature than $\mathrm{TdT}^{+} / \mathrm{S} 100$ cells. Martin-Martin et al[73] showed that patients with immature pDC phenotype $\left(\mathrm{CD} 34^{+/-}\right.$and $\mathrm{CD} 117^{- \text {dim }}$ with coexisting non-pDC lineage blast cells) exhibit a rare $\mathrm{CD} 56^{-}$phenotype, which are mixed with $\mathrm{CD} 34^{+}$ non-tumor cells, and typically manifest in disease that is confined to the bone marrow. Conversely, patients with a more mature blast cell phenotype (e.g., $\mathrm{CD} 34^{-\mathrm{CD}} 117^{\mathrm{dim}}$ is intermediately mature and $\mathrm{CD} 34^{-} \mathrm{CD} 117^{-}$is mature) more commonly have skin and extramedullary involvement and extension into secondary lymphoid tissues. These results exhibited a highly different mature profile of BPDC tumor cells, which led to a heterogeneous clinical behavior of alteration from acute leukemia to peripheral mature lymphomas. Because phenotypes and clinical manifestations overlap between BPDCN and other tumors, distinguishing BPDCN from other misleading diseases is important. Because there is no uniform understanding of BPDCN, we need further exploration of the immunophenotype of BPDCNs.

\section{CLINICAL COURSE AND TREATMENT OF BPDCN}

BPDCN is a heterogeneous disorder, and little is known about its clinical abnormalities, disease associations, treatments, and outcomes. No standard of care regimens has been well developed, but recently the largest review of BPDCN evaluated the effectiveness of various different treatment regimens in 357 patients, including 74 pediatric and 283 adult patients ${ }^{[90]}$. The results indicated that any type of chemotherapy or radiotherapy had better outcomes than no treatment, and the most effective chemotherapy regimens appeared to be those used to treat acute lymphoblastic leukemia. There was significantly higher remission rate for pediatric patients than for adult patients who received similar therapeutic regimens for acute lymphoblastic leukemia (93\% vs. 77\%, $P=0.04)$, AML $(77 \%$ vs. $47 \%, P=0.05)$, and lymphoma ( $80 \%$ vs. $53 \%, P=0.05)$. Children also were less likely than adult patients $(27 \%$ vs. $57 \%, P<0.01)$ to relapse after complete remission. We also listed the response rates and survival outcomes with different regimens of the main BPDCN patients reported in literature ${ }^{[8,73,75,86,91-95]}$ (table 2).

The challenge in treating BPDCN is that, despite a high frequency of initial complete remission with chemotherapy, relapse is common and overall survival is typically less than 2 years ${ }^{[74]}$. Allogenic stem cell transplantation has been shown to increase mean survival duration ${ }^{[8,74,90,96,97]}$. A systematic review of 128 patients receiving allo-hematopoietic cell transplantation for BPDCN was also reported ${ }^{[96]}$. The pooled 2-year overall survival rate was $50 \%$ for all patients. Among patients allografted in their first complete remission, pooled 4-year overall survival and progression-free survival/disease-free survival rates were $67 \%$ and $53 \%$, respectively. For patients allografted after the first complete remission, overall survival and progression-free survival/disease-free survival rates were $7 \%$ for both outcomes. Relapse rates were higher in patients treated with reduced intensity regimens than in those treated with myeloablative allohematopoietic cell transplantation regimens $(40 \% v s$. $18 \%$ ). Compared with conventional chemotherapy, hematopoietic stem cell transplantation is most likely to benefit survival. Allogeneic hematopoietic stem cell transplantation could be the most beneficial to survival after patient accepted the first complete remission; For those patients only eligible for autologous stem cell transplantation, autologous transplantation is recommended after the first remission.

Promising data were recently reported using targeting or immunomodulatory agents, including SL-401, bortezomib, and venetoclax, to treat BPDCN (table 3). The immunotoxin tagraxofusp (SL-401) targets the IL-3 receptor alpha (CD123), which is typically overexpressed by pDC blasts. Of the 47 patients with BPDCN who received tagraxofusp treatment, 32 patients had first-line treatment and 15 received previous treatment. Among the 29 previously untreated patients who received tagraxofusp, the primary outcome occurred in $21(72 \%)$, and the overall response rate was $90 \%$; survival rates at 18 and 24 months were $59 \%$ and $52 \%$, respectively. Among the 15 previously treated patients, the response rate was $67 \%$, and the median overall survival was 8.5 months. Until now, tagraxofusp was the first new target agent approved for BPDCN treatment ${ }^{[98,}{ }^{99]}$. Lenalidomide, in a mouse xenograft with BPDCN cells, reduced tumor growth by increasing apoptosis and cell cycle arrest and decreasing tumor cell engraftment and tumor vascularization $^{[100]}$. Bortezomib, a proteasome inhibitor, could significantly reduce BPDCN cell growth in vivo and in vitro; the drug also decreased phosphorylation of the NF- $\kappa \mathrm{B}$ subunit, RelA ${ }^{[19,101]}$. Recently, Marmouset et al described the use and value of a lenalidomide/ bortezomib/dexamethasone regimen for the treatment of three patients with BPDCN. After five cycles of chemotherapy, two patients obtained complete responses and one clinical remission ${ }^{[102]}$. Additionally, the BCL-2 inhibitor venetoclax increased apoptosis in BPDCN cells and survival in mouse xenograft models ${ }^{[103]}$. Montero et al reported two patients with relapsed/refractory BPDCN whose disease responded 
Table 2 Summary of studies on BPDCN patients treated with methods related with ALL/lymphoma-type, AML-type, palliative therapy and radiotherapy

\begin{tabular}{|c|c|c|c|c|c|c|}
\hline Treatment methods & $n$ & $\begin{array}{c}\text { CR } \\
n(\%)\end{array}$ & $\begin{array}{c}\text { Relapse } \\
n(\%)\end{array}$ & $\begin{array}{l}\text { Median relapse } \\
\text { (Mon, range) }\end{array}$ & $\begin{array}{c}\text { Median OS } \\
\text { (Mon, range) }\end{array}$ & References \\
\hline ALL/Lym-type & 16 & $14(87.5)$ & $10(71.4)$ & n.r. & $\begin{array}{c}\text { ALL-type: n.a.; } \\
\text { Lym-type: } 10(4-16)\end{array}$ & Martin-Martin et $a l^{[73]}$ \\
\hline AML-type & 9 & $9(100)$ & $7(77.8)$ & n.r. & $11(8-14)$ & \\
\hline ALL/Lym-type & 15 & $10(66.7)$ & $6(60)$ & n.r. & $12.3(1-32.9)$ & Pagano et al[75] \\
\hline AML-type & 26 & 7 (26.9) & $0(0)$ & n.r. & $7.1(0.2-19.5)$ & \\
\hline ALL/Lym-type & 13 & $11(84.6)$ & n.r. & n.r. & $12(4-21)$ & Hashikawa et al[94] \\
\hline AML-type & 4 & $0(0)$ & n.a. & n.a. & $5.5(1-18)$ & \\
\hline Radiotherapy & 4 & $3(75)$ & n.r. & n.r. & $6.5(3-14)$ & \\
\hline ALL/Lym-type & 13 & $9(69.2)$ & $4(44.4)$ & $20.5(11-36)$ & $13(8-72)$ & Lucioni et a $l^{[93]}$ \\
\hline Radiotherapy & 3 & $2(67)$ & $1(50)$ & 8 (n.a.) & $14(13-30)$ & \\
\hline Palliative therapy/None & 3 & $0(0)$ & n.a. & n.a. & $3(1-6)$ & \\
\hline ALL/Lym-type & 13 & $12(92.3)$ & $5(41.7)$ & n.r. & n.r. & Tsagarakis et al ${ }^{[92]}$ \\
\hline AML-type & 6 & $3(50)$ & $1(33.3)$ & n.r. & n.r. & \\
\hline Palliative therapy/None & 3 & $0(0)$ & n.a. & n.r. & n.r. & \\
\hline ALL/Lym-type & 20 & $16(80)$ & n.r. & n.r. & n.a. & Jegalian et a ${ }^{[91]}$ \\
\hline AML-type & 3 & n.r. & n.r. & n.r. & $6(2-37)$ & \\
\hline ALL/Lym-type & 26 & $14(53.8)$ & n.r. & $6(2-42)$ & $12(3-42)$ & Dalle et $a l^{[86]}$ \\
\hline AML-type & 12 & $5(41.7)$ & n.r. & $12(4-22)$ & $19(3-77)$ & \\
\hline Radiotherapy & 5 & $4(80)$ & n.r. & $5.5(2-9)$ & $19(8-36)$ & \\
\hline Palliative therapy/None & 4 & $0(0)$ & n.a. & n.a. & $2(1-12)$ & \\
\hline ALL/Lym-type & 15 & $12(80)$ & $9(75)$ & $6(4-12)$ & $12(4-98)$ & Feuillard et $a l^{[8]}$ \\
\hline AML-type & 6 & $6(100)$ & $6(100)$ & $10.5(3-18)$ & $14.5(5-37)$ & \\
\hline Palliative therapy/None & 2 & $0(0)$ & n.a. & n.a. & $3(3)$ & \\
\hline ALL/Lym-type & 131 & $98(74.8)$ & n.a. & n.a. & n.a. & Total \\
\hline AML-type & 66 & $30(47.6)$ & & & & \\
\hline Radiotherapy & 12 & $9(75)$ & & & & \\
\hline Palliative therapy/None & 12 & $0(0)$ & & & & \\
\hline
\end{tabular}

BPDCN: blastic plasmacytoid dendritic cell neoplasm; ALL: acute lymphoblastic leukemia; AML: acute myeloid leukemia; CR: complete remission; OS: overall survival; Mon: month; n.r.: not reported; n.a.: not available; Lym-type: lymphoma-type: C(H)OP: cyclophosphamide, (daunorubicin), vincristine, and prednisone regimen; DVLP: doxorubicin, vincristine, asparaginase, and prednisone; hyper-CVAD: hyperfractionated cyclophosphamide, vincristine, doxorubicin, and dexamethasone; DA: doxorubicin, cytarabine; IA: idarubicin, cytarabine

Table 3 New or potential therapy for BPDCN

\begin{tabular}{|c|c|c|c|c|}
\hline Regimen & Targeting & $n$ & Treatment outcomes & Status \\
\hline Tagraxofusp & IL-3 & 47 & $\begin{array}{l}\text { For } 21 \text { untreated patients, } 19(90 \%) \text { obtained ORR, and survival } \\
\text { rates at } 18 \text { and } 24 \text { months were } 59 \% \text { and } 52 \% \text { respectively; for } \\
\text { previously treated patients, } 10(67 \%) \text { obtained ORR, and median } \\
\text { OS was } 8.5 \text { months. }\end{array}$ & $\begin{array}{l}\text { A open-label, } \\
\text { multicohort phase } \\
\text { I - II study }\end{array}$ \\
\hline IMGN632 & IL-3 & NA & NA & Phase 1 underway \\
\hline $\mathrm{XmAb} 14045$ & IL-3 and CD3 & NA & NA & Phase 1 underway \\
\hline CAR-T cell & IL-3 & NA & NA & Phase 1 underway \\
\hline Lenalidomide & $\begin{array}{c}\text { Multiple } \\
\text { (angiogenesis, NF- } \mathrm{kB} \text { ) }\end{array}$ & NA & $\begin{array}{l}\text { Increased apoptosis, decreased cell engraftment and decreased } \\
\text { tumor vascularization }\end{array}$ & Preclinical trial \\
\hline Bortezomib & $\begin{array}{l}\text { Proteasome and } \\
\text { NF- } \mathrm{kB} \text { signaling }\end{array}$ & NA & $\begin{array}{l}\text { Decreased circulating BPDCN cells and RelA NF-kappaB } \\
\text { signaling, increased mouse survival }\end{array}$ & Preclinical trial \\
\hline Venetoclax & BCL-2 & 3 & $\begin{array}{l}\text { PR in } 2 \text { cases (at } 4 \text { weeks), CR in one case (at } 5 \text { months, response } \\
5 \text { months) }\end{array}$ & Preclinical trial \\
\hline
\end{tabular}

BPDCN: blastic plasmacytoid dendritic cell neoplasm; ORR: overall response rate; CR: complete remission; PR: partial remission; CAR-T cell: chimeric antigen receptor T cell; NA: not available

to venetoclax: both patients experienced a partial response at 4 weeks, suggesting BPDCN sensitivity to $\mathrm{BCL} 2$ inhibition $^{[103]}$. Another publication reported a patient with BPDCN who suffered a recurrence after combined cyclophosphamide, doxorubicin hydrochloride, vincristine sulfate, and prednisone therapy followed by autologous hematopoietic stem cell transplantation. His skin biopsy at the time of recurrence showed BCL-2 positive disease, and he achieved complete remission after 5 months of 
treatment with venetoclax and maintained complete remission at 10 months, which supports the potential effectiveness of venetoclax ${ }^{[104]}$. Quick complete response was achieved with venetoclax and azacitidine in a case of relapsed disseminated BPDCN ${ }^{[105]}$.

Other therapies are being evaluated that also target CD123, a novel antibody-drug conjugate, IMGN632, which incorporates an anti-CD123 antibody with a DNA-alkylating agent and has shown significant preclinical activity both in myeloid and lymphoblastic leukemia ${ }^{[106,107]}$. This is currently being evaluated in a phase 1 study for BPDCN (NCT03386513). A bispecific antibody, XmAb14045, targeting CD123 and CD3 has been developed that crosslinks CD123positive cancer cells to cytotoxic $\mathrm{T}$ lymphocytes, and is also being evaluated in a phase 1 trial that includes BPDCN patients. Chimeric antigen receptor $\mathrm{T}$ (CAR-T) cell therapy has shown promise for a number of hematologic malignancies, and CAR-T cells against CD123 have shown preclinical activity in AML models ${ }^{[108]}$. CD28/4-1BB CD123 CAR-T cells displayed strong efficacy and low or no cytotoxicity against various subsets of normal cells with low CD123 expression in $\mathrm{BPDCN}^{[109]}$. There are phase 1 trials underway to evaluate anti-CD123 CAR-T cell therapy in patients with BPDCN and AML (NCT03203369 and NCT02159495).

Recently, the development of bromodomain and extra-terminal domain inhibitors (BETis) has challenged the traditional notion that transcription factors cannot be targeted. BETis were shown to silence the expression of these BPDCN oncogenes causing their transcriptional control by "super-enhancers" (SEs), defined as large genomic clusters of bromodomain and extra-terminal domain (BET)-dependent regulatory regions. TCF4 acts as the major downstream target of BETis in BPDCN cells and is localized to the majority of SEs in BPDCN. BETis down-regulate several TCF4 targeted pDC-related genes, and TCF4 itself is strongly down-regulated by BETis, which may be correlated with the TCF4 locus containing a BPDCN-specific SE that is bound by BRD4. In addition, TCF4 knockdown reduces the expression of these SE-regulated genes. It is also demonstrated that ectopic TCF4 expression could rescue BPDCN cells from the toxicity of BETis. Thus, TCF4 controls a pleiotropic network of target genes in BPDCN, making it less likely that a genetic alteration targeting a single TCF4 target could overcome BETi toxicity. The application of BETis shed light on BPDCN treatment based on the strong mechanistic rational clinical evaluation ${ }^{[57]}$. Treatment with a liver $\mathrm{X}$ receptor agonist decreases leukemic cell infiltration and BPDCN-induced cytopenia while increases survival in a BPDCN cell mouse xenograft model ${ }^{[110]}$. Therefore, more research is needed to better understand the effect mechanisms of these treatments and develop predictive markers and combination strategies.

Data on predictive factors of BPDCNs are currently unavailable. Survival analyses showed that CD303 expression, levels of TdT expression greater than $50 \%$, and $\mathrm{Ki}-67$ index higher than $67 \%$ were significantly associated with longer survival in BPDCN patients $^{[82]}$, while $9 \mathrm{p} 21.3$ deletion was associated with shorter overall survival ${ }^{[93]}$. Therefore, high Ki-67 and TdT expression may prolong survival. Previous publications have reported that pediatric patients without skin infiltration were expected to have better outcomes than their counterparts with skin infiltration, whereas this manifestation was not correlated with a difference in outcomes in adults ${ }^{[111]}$. But the clinical presentation of BPDCN at the time of diagnosis in children does not differ from that in adults, especially in regard to the organs involved. Notably, younger age is an independent favorable prognostic indicator across all prognostic measures for BPDCN, including response to first-line chemotherapy, relapse rate and overall survival. In patients older than 63.5 years, the possibility of a negative result is higher ${ }^{[00]}$. However, patients with central nervous system involvement do not show a statistically different relapse rate compared with those without ${ }^{[90]}$, in contrast to the viewpoint that central nervous system involvement may have an impact on event-free survival time ${ }^{[8]}$. Based on the evidence as above, algorithm to guide the therapeutic strategy in patients with BPDCN is summarized in fig. 6.

\section{CONCLUSION}

BPDCNs originate from pDCs. However, the pDC population is divided into two subsets called pure pDCs and pDC-like cells. pDC-like cells show strong capacity for stimulating $\mathrm{T}$ cell proliferation, whereas pure $\mathrm{pDCs}$ ' main function is secretion of IFN1. Additionally, pDC-like cells come from CDPs, and pure pDCs from IL-7R $\alpha^{+} \mathrm{Ly} 6 \mathrm{D}^{+} \mathrm{SiglecH}^{+}$cells, suggesting that developmental encoding could exist, and in-depth research is needed. The genetic and immunophenotypic properties of BPDCNs overlap with those of pDCs and cDCs. PDC-derived tumors are rare and manifest in two main different clinical entities. The mature $\mathrm{pDC}$ neoplasms are associated with myeloid neoplasm while the highly aggressive BPDCNs show a distinctive cutaneous manifestation followed by rapid systemic dissemination, a heterogeneous phenotypic profile, complex but non-specific chromosome and genetic alterations, and poor prognosis. Chemotherapy regimens used for ALL have been shown to be the most effective treatment, while allo-hematopoietic stem cell transplantation can prolong survival across all age groups. High levels of expression of CD303, Ki-67, and TdT may prolong survival, whereas 9p21.3 deletion 


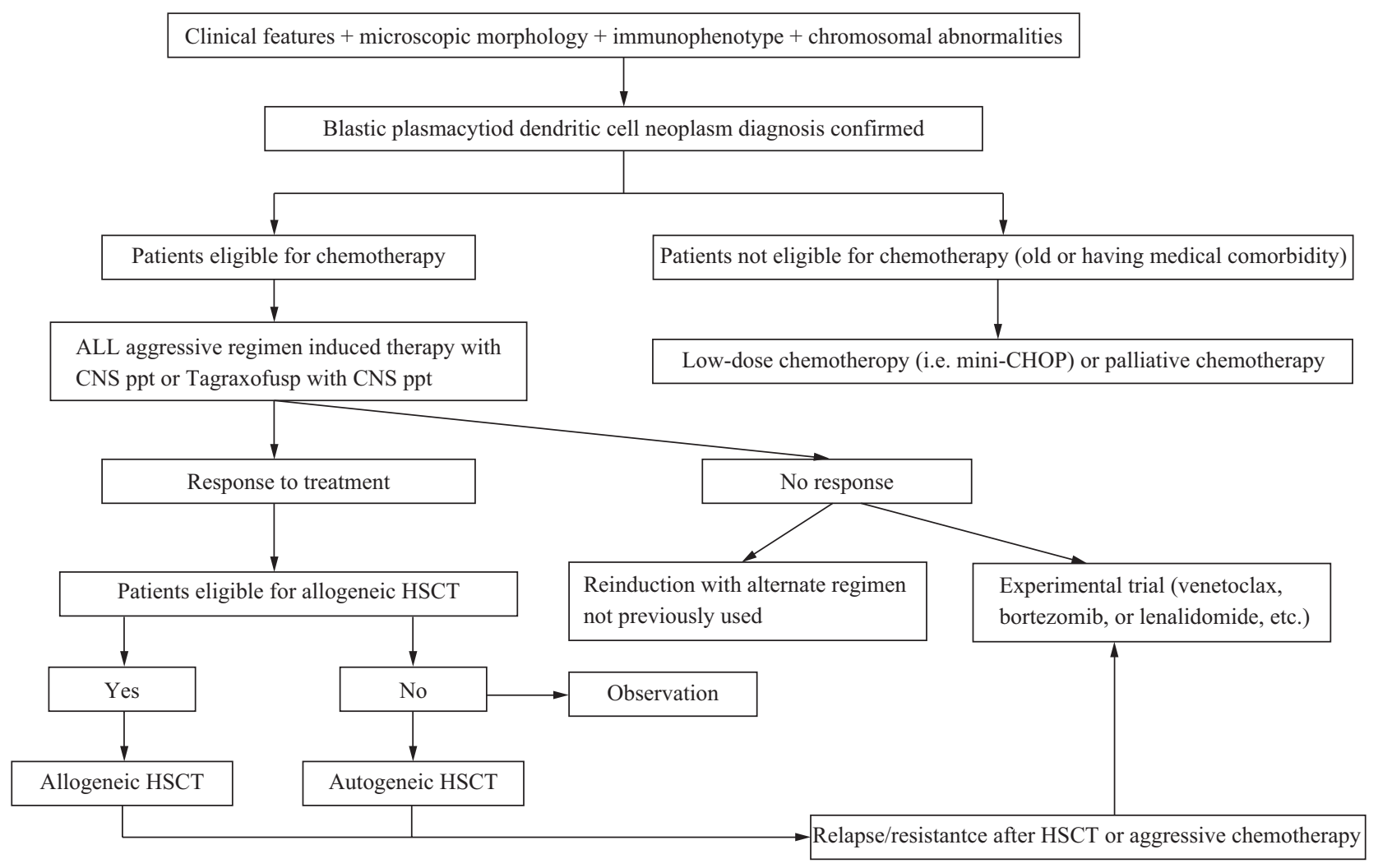

Fig. 6 Proposed algorithm to guide the therapeutic strategy in patients with BPDCN

Adults eligible for chemotherapy may be considered for SL-401 or intensity conditioning regimens of ALL-type aggressive regimen induced therapy (i.e, VDLP, Hyper-CVAD), ALL-type and AML-type consolidation. Adults eligible for chemotherapy may be treated with low-dose chemotherapy or palliative chemotherapy. Allogenic or autogenetic stem cell transplantation can increase mean survival duration. Experimental trial (venetoclax, bortezomib, or lenalidomide, etc.) serves as the option of relapse/ resistantce after HSCT or aggressive chemotherapy. AML: acute myeloid leukemia; ALL: acute lymphoblastic leukemia; Ara-C: cytarabine; HSCT: hematopoietic stem cell transplantation; Hyper-CVAD: hyperfractionated cyclophosphamide, vincristine, adriamycin, and dexamethasone/methotrexate and cytarabine

has been associated with shorter overall survival.

Promising preclinical and clinical results have been published about BPDCN, including that target surface receptors (i.e., CD123) or inhibitors of aberrantly activated survival pathways (i.e., NF- $\mathrm{kB}$ ). BETis bring new sight for BPDCN treatment, other new treatments such as CAR-T cell therapy and liver X receptor agonists have been proposed, but, because of the rare incidence of the disease, progress in preclinical research for various targeted or immunomodulatory agents is slow, and the differences between monotherapy or combination therapy still need further exploration. Studies of biomarkers and immune monitoring are ongoing and may benefit future patients with BPDCN.

\section{Open Access}

This article is licensed under a Creative Commons Attribution 4.0 International License https://creativecommons.org/licenses/by/4.0/), which permits use, sharing, adaptation, distribution and reproduction in any medium or format, as long as you give appropriate credit to the original author(s) and the source, provide a link to the Creative Commons licence, and indicate if changes were made. The images or other third party material in this article are included in the article's Creative Commons licence, unless indicated otherwise in a credit line to the material. If material is not included in the article's Creative Commons licence and your intended use is not permitted by statutory regulation or exceeds the permitted use, you will need to obtain permission directly from the copyright holder. To view a copy of this licence, visit http://creativecommons. org/licenses/by/4.0/.

\section{Conflict of Interest Statement}

The authors declared they had no conflicts of interest to this work.

\section{REFERENCES}

1 Adachi M, Maeda K, Takekawa M, et al. High expression of CD56 (N-CAM) in a patient with cutaneous CD4positive lymphoma. Am J Hematol, 1994,47(4):278-282

2 Brody JP, Allen S, Schulman P, et al. Acute agranular CD4-positive natural killer cell leukemia. Comprehensive clinicopathologic studies including virologic and in vitro culture with inducing agents. Cancer, 1995,75(10):2474-2483

3 Petrella T, Dalac S, Maynadié M, et al. CD4+ CD56+ cutaneous neoplasms: a distinct hematological entity? Groupe Français d'Etude des Lymphomes Cutanés 
(GFELC). Am J Surg Pathol, 1999,23(2):137-146

4 Aoyama Y, Yamane T, Hino M, et al. Blastic NKcell lymphoma/leukemia with T-cell receptor gamma rearrangement. Ann Hematol, 2001,80(12):752-754

5 Vardiman JW, Thiele J, Arber DA, et al. The 2008 revision of the World Health Organization (WHO) classification of myeloid neoplasms and acute leukemia: rationale and important changes. Blood, 2009,114(5): 937-951

6 Arber DA, Orazi A, Hasserjian R, et al. The 2016 revision to the World Health Organization classification of myeloid neoplasms and acute leukemia. Blood, 2016, 127(20):2391-2405

7 Chaperot L, Bendriss N, Manches O, et al. Identification of a leukemic counterpart of the plasmacytoid dendritic cells. Blood, 2001,97(10):3210-3217

8 Feuillard J, Jacob MC, Valensi F, et al. Clinical and biologic features of $\mathrm{CD} 4(+) \mathrm{CD} 56(+)$ malignancies. Blood, 2002,99(5):1556-1563

9 Petrella T, Comeau MR, Maynadié M, et al. 'Agranular $\mathrm{CD} 4+\mathrm{CD} 56+$ hematodermic neoplasm' (blastic NKcell lymphoma) originates from a population of CD56+ precursor cells related to plasmacytoid monocytes. Am J Surg Pathol, 2002,26(7):852-862

10 Jacob MC, Chaperot L, Mossuz P, et al. CD4+ CD56+ lineage negative malignancies: a new entity developed from malignant early plasmacytoid dendritic cells. Haematologica, 2003,88(8):941-955

11 Dzionek A, Sohma Y, Nagafune J, et al. BDCA-2, a novel plasmacytoid dendritic cell-specific type II C-type lectin, mediates antigen capture and is a potent inhibitor of interferon alpha/beta induction. J Exp Med, 2001,194(12):1823-1834

12 Herling M, Teitell MA, Shen RR, et al. TCL1 expression in plasmacytoid dendritic cells (DC2s) and the related CD4+ CD56+ blastic tumors of skin. Blood, 2003,101(12):5007-5009

13 Jaye DL, Geigerman CM, Herling M, et al. Expression of the plasmacytoid dendritic cell marker BDCA-2 supports a spectrum of maturation among CD4+ CD56+ hematodermic neoplasms. Mod Pathol, 2006,19(12): 1555-1562

14 Marafioti T, Paterson JC, Ballabio E, et al. Novel markers of normal and neoplastic human plasmacytoid dendritic cells. Blood, 2008,111(7):3778-3792

15 Sasaki I, Hoshino K, Sugiyama T, et al. Spi-B is critical for plasmacytoid dendritic cell function and development. Blood, 2012,120(24):4733-4743

16 Boiocchi L, Lonardi S, Vermi W, et al. BDCA-2 (CD303): a highly specific marker for normal and neoplastic plasmacytoid dendritic cells. Blood, 2013, 122(2):296-297

17 Montes-Moreno S, Ramos-Medina R, MartínezLópez A, et al. SPIB, a novel immunohistochemical marker for human blastic plasmacytoid dendritic cell neoplasms: characterization of its expression in major hematolymphoid neoplasms. Blood, 2013,121(4):643647

18 Facchetti F, Cigognetti M, Fisogni S, et al. Neoplasms derived from plasmacytoid dendritic cells. Mod Pathol, 2016,29(2):98-111

19 Sapienza MR, Fuligni F, Agostinelli C, et al. Molecular profiling of blastic plasmacytoid dendritic cell neoplasm reveals a unique pattern and suggests selective sensitivity to NF-kB pathway inhibition. Leukemia, 2014,28(8): 1606-1616

20 Lennert K, Remmele W. Karyometric research on lymph node cells in man. I. Germinoblasts, lymphoblasts \& lymphocytes. Acta Haematol, 1958,19(2):99-113

21 Facchetti F, Vermi W, Mason D, et al. The plasmacytoid monocyte/interferon producing cells. Virchows Arch, 2003,443(6):703-717

22 Facchetti F, de Wolf-Peeters C, Mason DY, et al. Plasmacytoid $\mathrm{T}$ cells. Immunohistochemical evidence for their monocyte/macrophage origin. Am J Pathol, 1988,133(1):15-21

23 Cella M, Jarrossay D, Facchetti F, et al. Plasmacytoid monocytes migrate to inflamed lymph nodes and produce large amounts of type I interferon. Nat Med, 1999,5(8):919-923

24 Rissoan MC, Soumelis V, Kadowaki N, et al. Reciprocal control of T helper cell and dendritic cell differentiation. Science, 1999,283(5405):1183-1186

25 Siegal FP, Kadowaki N, Shodell M, et al. The nature of the principal type 1 interferon-producing cells in human blood. Science, 1999,284(5421):1835-1837

26 Haniffa M, Collin M, Ginhoux F. Ontogeny and functional specialization of dendritic cells in human and mouse. Adv Immunol, 2013,120:1-49

27 Soumelis V, Liu YJ. From plasmacytoid to dendritic cell: morphological and functional switches during plasmacytoid pre-dendritic cell differentiation. Eur J Immunol, 2006,36(9):2286-2292

28 Facchetti F, De Wolf-Peeters C, van den Oord JJ, et al. Plasmacytoid T cells: a cell population normally present in the reactive lymph node. An immunohistochemical and electronmicroscopic study. Hum Pathol, 1988,19(9): 1085-1092

29 Jing Y, Shaheen E, Drake RR, et al. Aging is associated with a numerical and functional decline in plasmacytoid dendritic cells, whereas myeloid dendritic cells are relatively unaltered in human peripheral blood. Hum Immunol, 2009,70(10):777-784

30 Jegalian AG, Facchetti F, Jaffe ES. Plasmacytoid dendritic cells: physiologic roles and pathologic states. Adv Anat Pathol, 2009,16(6):392-404

31 Vermi W, Lonardi S, Morassi M, et al. Cutaneous distribution of plasmacytoid dendritic cells in lupus erythematosus. Selective tropism at the site of epithelial apoptotic damage. Immunobiology, 2009,214(9-10): 877-886

32 Sozzani S, Vermi W, Del Prete A, et al. Trafficking properties of plasmacytoid dendritic cells in health and disease. Trends Immunol, 2010,31(7):270-277

33 Vermi W, Soncini M, Melocchi L, et al. Plasmacytoid dendritic cells and cancer. J Leukoc Biol, 2011,90(4):681690

34 Fogg DK, Sibon C, Miled C, et al. A clonogenic bone marrow progenitor specific for macrophages and dendritic cells. Science, 2006,311(5757):83-87

35 Naik SH, Sathe P, Park HY, et al. Development of plasmacytoid and conventional dendritic cell subtypes from single precursor cells derived in vitro and in vivo. Nat Immunol, 2007,8(11):1217-1226 
36 Onai N, Obata-Onai A, Schmid MA, et al. Identification of clonogenic common Flt3+M-CSFR+ plasmacytoid and conventional dendritic cell progenitors in mouse bone marrow. Nat Immunol, 2007,8(11):1207-1216

37 Sathe P, Metcalf D, Vremec D, et al. Lymphoid tissue and plasmacytoid dendritic cells and macrophages do not share a common macrophage-dendritic cellrestricted progenitor. Immunity, 2014,41(1):104-115

38 Liu K, Victora GD, Schwickert TA, et al. In vivo analysis of dendritic cell development and homeostasis. Science, 2009,324(5925):392-397

39 Onai N, Kurabayashi K, Hosoi-Amaike M, et al. A clonogenic progenitor with prominent plasmacytoid dendritic cell developmental potential. Immunity, 2013, 38(5):943-957

40 Murphy TL, Grajales-Reyes GE, Wu X, et al. Transcriptional Control of Dendritic Cell Development. Annu Rev Immunol, 2016,34:93-119

41 Rodrigues PF, Alberti-Servera L, Eremin A, et al. Distinct progenitor lineages contribute to the heterogeneity of plasmacytoid dendritic cells. Nat Immunol, 2018,19(7):711-722

42 Manz MG. Plasmacytoid dendritic cells: origin matters. Nat Immunol, 2018,19(7):652-654

43 D'Amico A, Wu L. The early progenitors of mouse dendritic cells and plasmacytoid predendritic cells are within the bone marrow hemopoietic precursors expressing Flt3. J Exp Med, 2003,198(2):293-303

44 Karsunky H, Merad M, Cozzio A, et al. Flt3 ligand regulates dendritic cell development from Flt3+ lymphoid and myeloid-committed progenitors to Flt3+ dendritic cells in vivo. J Exp Med, 2003,198(2):305-313

45 Cisse B, Caton ML, Lehner M, et al. Transcription factor E2-2 is an essential and specific regulator of plasmacytoid dendritic cell development. Cell, 2008, 135(1):37-48

46 Nagasawa M, Schmidlin H, Hazekamp MG, et al. Development of human plasmacytoid dendritic cells depends on the combined action of the basic helixloop-helix factor E2-2 and the Ets factor Spi-B. Eur J Immunol, 2008,38(9):2389-2400

47 Ghosh HS, Cisse B, Bunin A, et al. Continuous expression of the transcription factor e2-2 maintains the cell fate of mature plasmacytoid dendritic cells. Immunity, 2010,33(6):905-916

48 Reizis B. Regulation of plasmacytoid dendritic cell development. Curr Opin Immunol, 2010,22(2):206-211

49 Belz GT, Nutt SL. Transcriptional programming of the dendritic cell network. Nat Rev Immunol, 2012,12(2): 101-113

50 Li HS, Yang CY, Nallaparaju KC, et al. The signal transducers STAT5 and STAT3 control expression of Id 2 and E2-2 during dendritic cell development. Blood, 2012,120(22):4363-4673

51 Colonna M, Trinchieri G, Liu YJ. Plasmacytoid dendritic cells in immunity. Nat Immunol, 2004,5(12):1219-1226

52 Honda K, Yanai H, Negishi H, et al. IRF-7 is the master regulator of type-I interferon-dependent immune responses. Nature, 2005,434(7034):772-777

53 Blasius AL, Beutler B. Intracellular toll-like receptors. Immunity, 2010,32(3):305-315

54 Kawai T, Akira S. The role of pattern-recognition receptors in innate immunity: update on Toll-like receptors. Nat Immunol, 2010,11(5):373-384

55 Beird HC, Khan M, Wang F, et al. Features of nonactivation dendritic state and immune deficiency in blastic plasmacytoid dendritic cell neoplasm (BPDCN). Blood Cancer J, 2019,9(12):99

56 Villani AC, Satija R, Reynolds G, et al. Single-cell RNA-seq reveals new types of human blood dendritic cells, monocytes, and progenitors. Science, 2017, 356(6335):1-31

57 Ceribelli M, Hou ZE, Kelly PN, et al. A Druggable TCF4- and BRD4-Dependent Transcriptional Network Sustains Malignancy in Blastic Plasmacytoid Dendritic Cell Neoplasm. Cancer Cell, 2016,30(5):764-778

58 Tang Z, Tang G, Wang SA, et al. Simultaneous deletion of 3'ETV6 and 5'EWSR1 genes in blastic plasmacytoid dendritic cell neoplasm: case report and literature review. Mol Cytogenet, 2016,9:23

59 Leroux D, Mugneret F, Callanan M, et al. CD4(+), CD56(+) DC2 acute leukemia is characterized by recurrent clonal chromosomal changes affecting 6 major targets: a study of 21 cases by the Groupe Français de Cytogénétique Hématologique. Blood, 2002,99(11): 4154-4159

60 Dijkman R, van Doorn R, Szuhai K, et al. Geneexpression profiling and array-based CGH classify CD4+CD56+ hematodermic neoplasm and cutaneous myelomonocytic leukemia as distinct disease entities. Blood, 2007,109(4):1720-1727

61 Alayed K, Patel KP, Konoplev S, et al. TET2 mutations, myelodysplastic features, and a distinct immunoprofile characterize blastic plasmacytoid dendritic cell neoplasm in the bone marrow. Am J Hematol, 2013,88(12):10551061

62 Menezes J, Acquadro F, Wiseman M, et al. Exome sequencing reveals novel and recurrent mutations with clinical impact in blastic plasmacytoid dendritic cell neoplasm. Leukemia, 2014,28(4):823-829

63 Stenzinger A, Endris V, Pfarr N, et al. Targeted ultra-deep sequencing reveals recurrent and mutually exclusive mutations of cancer genes in blastic plasmacytoid dendritic cell neoplasm. Oncotarget, 2014,5(15):64046413

64 Sakamoto K, Katayama R, Asaka R, et al. Recurrent 8 q24 rearrangement in blastic plasmacytoid dendritic cell neoplasm: association with immunoblastoid cytomorphology, MYC expression, and drug response. Leukemia, 2018,32(12):2590-2603

65 Sumarriva Lezama L, Chisholm KM, Carneal E, et al. An analysis of blastic plasmacytoid dendritic cell neoplasm with translocations involving the MYC locus identifies $\mathrm{t}(6 ; 8)(\mathrm{p} 21 ; \mathrm{q} 24)$ as a recurrent cytogenetic abnormality. Histopathology, 2018,73(5):767-776

66 Tang Z, Li Y, Wang W, et al. Genomic aberrations involving 12p/ETV6 are highly prevalent in blastic plasmacytoid dendritic cell neoplasms and might represent early clonal events. Leuk Res, 2018,73:86-94

67 Zhang X, Sun J, Yang M, et al. New perspectives in genetics and targeted therapy for blastic plasmacytoid dendritic cell neoplasm. Crit Rev Oncol Hematol, 2020, 149:102928

68 Jardin F, Callanan M, Penther D, et al. Recurrent 
genomic aberrations combined with deletions of various tumour suppressor genes may deregulate the G1/S transition in CD4+CD56+ haematodermic neoplasms and contribute to the aggressiveness of the disease. Leukemia, 2009,23(4):698-707

69 Abdel-Wahab O, Levine RL. Mutations in epigenetic modifiers in the pathogenesis and therapy of acute myeloid leukemia. Blood, 2013,121(18):3563-3572

70 Li M, Shah M, Binder M, et al. Cutaneous blastic plasmacytoid dendritic cell neoplasm arising in the context of TET2 and ZRSR2 mutated clonal cytopenias of unknown significance, secondary to somatic copy number losses involving CDK2NA/2NB and MTAP. Am J Hematol, 2020,95(2):E31-E34

71 Bueno C, Almeida J, Lucio $\mathrm{P}$, et al. Incidence and characteristics of CD4(+)/HLA DRhi dendritic cell malignancies. Haematologica, 2004,89(1):58-69

72 Khoury JD. Blastic Plasmacytoid Dendritic Cell Neoplasm. Curr Hematol Malig Rep, 2018,13(6):477483

73 Martín-Martín L, López A, Vidriales B, et al. Classification and clinical behavior of blastic plasmacytoid dendritic cell neoplasms according to their maturation-associated immunophenotypic profile. Oncotarget, 2015,6(22):19204-19216

74 Julia F, Petrella T, Beylot-Barry M, et al. Blastic plasmacytoid dendritic cell neoplasm: clinical features in 90 patients. Br J Dermatol, 2013,169(3):579-586

75 Pagano L, Valentini CG, Pulsoni A, et al. Blastic plasmacytoid dendritic cell neoplasm with leukemic presentation: an Italian multicenter study. Haematologica, 2013,98(2):239-246

76 Martín-Martín L, Almeida J, Pomares H, et al. Blastic plasmacytoid dendritic cell neoplasm frequently shows occult central nervous system involvement at diagnosis and benefits from intrathecal therapy. Oncotarget, 2016,7(9):10174-10181

77 Feng Z, Zhou J, Bentley G. Blastic plasmacytoid dendritic cell neoplasm: report of a case presenting with lung and central nervous system involvement and review of the literature. J La State Med Soc, 2014,166(1):2-9

78 Rauh MJ, Rahman F, Good D, et al. Blastic plasmacytoid dendritic cell neoplasm with leukemic presentation, lacking cutaneous involvement: Case series and literature review. Leuk Res, 2012,36(1):81-86

79 Wang H, Cao J, Hong X. Blastic plasmacytoid dendritic cell neoplasm without cutaneous lesion at presentation: case report and literature review. Acta Haematol, 2012, 127(2):124-127

80 Khoury JD, Medeiros LJ, Manning JT, et al. CD56(+) TdT(+) blastic natural killer cell tumor of the skin: a primitive systemic malignancy related to myelomonocytic leukemia. Cancer, 2002,94(9):24012408

81 Cota C, Vale E, Viana I, et al. Cutaneous manifestations of blastic plasmacytoid dendritic cell neoplasmmorphologic and phenotypic variability in a series of 33 patients. Am J Surg Pathol, 2010,34(1):75-87

82 Julia F, Dalle S, Duru G, et al. Blastic plasmacytoid dendritic cell neoplasms: clinico-immunohistochemical correlations in a series of 91 patients. Am J Surg Pathol, 2014,38(5):673-680
83 Petrella T, Bagot M, Willemze R, et al. Blastic NK-cell lymphomas (agranular CD4+CD56+ hematodermic neoplasms): a review. Am JClin Pathol, 2005,123(5):662675

84 Emadali A, Hoghoughi N, Duley S, et al. Haploinsufficiency for NR3C1, the gene encoding the glucocorticoid receptor, in blastic plasmacytoid dendritic cell neoplasms. Blood, 2016,127(24):30403053

85 Garnache-Ottou F, Feuillard J, Ferrand C, et al. Extended diagnostic criteria for plasmacytoid dendritic cell leukaemia. Br J Haematol, 2009,145(5):624-636

86 Dalle S, Beylot-Barry M, Bagot M, et al. Blastic plasmacytoid dendritic cell neoplasm: is transplantation the treatment of choice. Br J Dermatol, 2010,162(1):7479

87 Angelot-Delettre F, Biichle S, Ferrand C, et al. Intracytoplasmic detection of TCL1--but not ILT7by flow cytometry is useful for blastic plasmacytoid dendritic cell leukemia diagnosis. Cytometry A, 2012, 81(8):718-724

88 Salva KA, Haemel AK, Pincus LB, et al. Expression of CD31/PECAM-1 (platelet endothelial cell adhesion molecule 1) by blastic plasmacytoid dendritic cell neoplasms. JAMA Dermatol, 2014,150(1):73-76

89 Wang W, Khoury JD, Miranda $\mathrm{RN}$, et al. Immunophenotypic characterization of reactive and neoplastic plasmacytoid dendritic cells permits establishment of a 10-color flow cytometric panel for initial workup and residual disease evaluation of blastic plasmacytoid dendritic cell neoplasm. Haematologica, 2020.105:1-24

90 Kim MJ, Nasr A, Kabir B, et al. Pediatric Blastic Plasmacytoid Dendritic Cell Neoplasm: A Systematic Literature Review. J Pediatr Hematol Oncol, 2017,39(7): 528-537

91 Jegalian AG, Buxbaum NP, Facchetti F, et al. Blastic plasmacytoid dendritic cell neoplasm in children: diagnostic features and clinical implications. Haematologica, 2010,95(11):1873-1879

92 Tsagarakis NJ, Kentrou NA, Papadimitriou KA, et al. Acute lymphoplasmacytoid dendritic cell (DC2) leukemia: results from the Hellenic Dendritic Cell Leukemia Study Group. Leuk Res, 2010,34(4):438-446

93 Lucioni M, Novara F, Fiandrino G, et al. Twenty-one cases of blastic plasmacytoid dendritic cell neoplasm: focus on biallelic locus 9p21.3 deletion. Blood, 2011, 118(17):4591-4594

94 Hashikawa K, Niino D, Yasumoto S, et al. Clinicopathological features and prognostic significance of CXCL12 in blastic plasmacytoid dendritic cell neoplasm. J Am Acad Dermatol, 2012,66(2):278-291

95 Laribi K, Baugier de Materre A, Sobh M, et al. Blastic plasmacytoid dendritic cell neoplasms: results of an international survey on 398 adult patients. Blood Adv, 2020,4(19):4838-4848

96 Kharfan-Dabaja MA, Reljic T, Murthy HS, et al. Allogeneic Hematopoietic Cell Transplantation Is an Effective Treatment for Blastic Plasmacytoid Dendritic Cell Neoplasm in First Complete Remission: Systematic Review and Meta-analysis. Clin Lymphoma Myeloma Leuk, 2018,18(11):703-709 
97 Yun S, Chan O, Kerr D, et al. Survival outcomes in blastic plasmacytoid dendritic cell neoplasm by firstline treatment and stem cell transplant. Blood Adv, 2020,4(14):3435-3442

98 Pemmaraju N, Lane AA, Sweet KL, et al. Tagraxofusp in Blastic Plasmacytoid Dendritic-Cell Neoplasm. N Engl J Med, 2019,380(17):1628-1637

99 Jen EY, Gao X, Li L, et al. FDA Approval Summary: Tagraxofusp-erzs For Treatment of Blastic Plasmacytoid Dendritic Cell Neoplasm. Clin Cancer Res, 2020,26(3): 532-536

100 Agliano A, Martin-Padura I, Marighetti P, et al. Therapeutic effect of lenalidomide in a novel xenograft mouse model of human blastic NK cell lymphoma/ blastic plasmacytoid dendritic cell neoplasm. Clin Cancer Res, 2011,17(19):6163-6173

101 Philippe L, Ceroi A, Bôle-Richard E, et al. Bortezomib as a new therapeutic approach for blastic plasmacytoid dendritic cell neoplasm. Haematologica, 2017,102(11):1861-1868

102 Marmouset V, Joris M, Merlusca L, et al. The lenalidomide/bortezomib/dexamethasone regimen for the treatment of blastic plasmacytoid dendritic cell neoplasm. Hematol Oncol, 2019,37(4):487-489

103 Montero J, Stephansky J, Cai T, et al. Blastic Plasmacytoid Dendritic Cell Neoplasm Is Dependent on BCL2 and Sensitive to Venetoclax. Cancer Discov, 2017,7(2):156-164

104 Grushchak S, Joy C, Gray A, et al. Novel treatment of blastic plasmacytoid dendritic cell neoplasm: A case report. Medicine (Baltimore), 2017,96(51):e9452
105 Piccini M, Loscocco GG, Gianfaldoni G, et al. Quick complete response achievement with venetoclax and azacitidine in a case of relapsed disseminated blastic plasmacytoid dendritic cell neoplasm. Ann Hematol, 2020,99(4):907-909

106 Kovtun Y, Jones GE, Adams S, et al. A CD123-targeting antibody-drug conjugate, IMGN632, designed to eradicate AML while sparing normal bone marrow cells. Blood Adv, 2018,2(8):848-858

107 Angelova E, Audette C, Kovtun Y, et al. CD123 expression patterns and selective targeting with a CD123-targeted antibody-drug conjugate (IMGN632) in acute lymphoblastic leukemia. Haematologica, 2019, 104(4):749-755

108 Gill S, Tasian SK, Ruella M, et al. Preclinical targeting of human acute myeloid leukemia and myeloablation using chimeric antigen receptor-modified $\mathrm{T}$ cells. Blood, 2014,123(15):2343-2354

109 Bôle-Richard E, Fredon M, Biichlé S, et al. CD28/41BB CD123 CAR $\mathrm{T}$ cells in blastic plasmacytoid dendritic cell neoplasm. Leukemia, 2020,34(12):32283241

110 Ceroi A, Masson D, Roggy A, et al. LXR agonist treatment of blastic plasmacytoid dendritic cell neoplasm restores cholesterol efflux and triggers apoptosis. Blood, 2016,128(23):2694-2707

111 Shi Y, Wang E. Blastic plasmacytoid dendritic cell neoplasm: a clinicopathologic review. Arch Pathol Lab Med, 2014,138(4):564-569

(Received Apr. 3, 2021; accepted Jun. 23, 2021) 